\title{
From one rapeseed congress to another: what research for which issues, A review of the Saskatoon 2015 conference in the perspective of Berlin 2019 许, 动
}

\author{
Etienne Pilorgé $^{1, *}$, Francis Flénet ${ }^{1}$, Alain Quinsac $^{2}$ and Xavier Pinochet ${ }^{1}$ \\ 1 Terres Inovia, F 78850 Thiverval-Grignion, France \\ 2 Terres Inovia, F 33600 Pessac, France
}

Received 14 January 2019 - Accepted 4 June 2019

\begin{abstract}
The contents of the 2015 Rapeseed Convention, held in Saskatoon, Canada, under the auspices of GCIRC, provided an up-to-date review of rapeseed research and innovation and development perspectives, which may key to understanding the evolutions that will be expressed during the 15th Colza Congress, in Berlin, Germany, in June 2019, in a context marked both by the emergence of new technologies and by changes in market and societal demand.
\end{abstract}

Keywords: rapeseed / canola / process / protein / genetics / sustainable production

Résumé - D'un congrès colza à l'autre : quelles recherches pour quels enjeux, Une relecture du congrès de Saskatoon 2015 dans la perspective de Berlin 2019. Les contenus du congrès Colza de 2015, qui s'est tenu à Saskatoon, Canada, sous l'égide du GCIRC, fournissaient un état des lieux à date de la recherche-innovation sur le colza et des perspectives de développement, qui peuvent offrir une clé de lecture des évolutions qui s'exprimeront lors du $15^{\mathrm{e}}$ congrès Colza, à Berlin, Allemagne, en juin 2019, dans un contexte marqué à la fois par l'émergence de nouvelles technologies et par les évolutions de la demande des marchés et des sociétés (the full text is available in French on https://www.ocl-journal.org/ 10.1051/ocl/2019026).

Mots clés : colza / canola / procédés / protéines / génétique / production durable

\section{Introduction}

Every four years, the world of Research and Innovation on rapeseed and canola meets under the auspices of the GCIRC (International Consultative Group for Research on Rapeseed) to take stock of the progress of research and development and of the sector issues. Can the contents of the 2015 conference, held in Saskatoon, Canada, give us some keys to understanding the research and innovation dynamics that will be presented in Berlin in June 2019?

The 14th International Rapeseed Congress welcomed 853 participants from 31 countries. In addition to the strong presence of the organizing country, the main delegations came from China, Germany, USA, India, France, Australia, Great Britain.

\footnotetext{
Contribution to the Topical Issue "Rapeseed / Colza"

the French version is available in "Supplementary Material".

*Correspondence: e.pilorge@terresinovia.fr
}

Co-organized by Ag-West Bio Inc. (Saskatchewan's Bioscience Industry Association, www.agwest.sk.ca) and the Canola Council of Canada (www.canolacouncil.org), the conference allowed the cross-cutting of sectoral issues and of research dynamics, with a focus on the progress made by knowledge and technological innovations in response to the needs of markets and consumers, international regulations and environmental issues.

In addition to the 5 presentations in the plenary session and the 35 oral presentations in Keynotes, the Congress was the setting for 498 papers on 5 themes: 175 presentations on genetics, genomics and selection (44 oral and 131 posters), 124 on crop protection, biotic stresses, and pest biology (40 oral, 84 posters), 72 seed analysis, processing methods, and outlets, (28 oral, 44 posters), 113 on agronomy, abiotic stresses and environmental impacts ( 25 oral, 88 posters), 14 on economics, politics and trade (10 oral, 4 posters).

Nine non-program workshops were also organized on the margins of the Congress on topics that are very active in terms of research and/or corresponding to major challenges, namely: "Leptosphaeria", "Brassica carinata", "emerging technologies", 
"Integrated Protection IPM", "Rhizosphere and Microbiome", "Varietal Assessment Networks", "Pollinator Health", and "Rapeseed Protein".

\section{At the crossroads of market issues and sustainability of production, genetic progress in the game of societal and regulatory controversies}

Peter Philips (University of Saskatchewan) noted in his Keynote that canola is a "designer" crop, for which innovation was based on science, especially genetics: after the double zero, rapeseed was part of the first wave of genetically modified crops, herbicide-tolerant (HT) cultivars, followed by varieties for new oils with modified fatty acid profiles, and then in the third generation would come the Plant-Made Pharmaceutical (PMP).

Knowledge on genetics of rapeseed and related species and genetic improvement accounted for nearly 30\% of communications and reported several major advances, starting with the publication in 2014 of the rapeseed genome reference sequence (Chalhoub et al., 2014) ${ }^{1}$.

In the field of genome exploration, a dozen papers have focused on Genome Wide Association Studies (GWAS) and reflect both efforts to go beyond reference sequences, to obtain maps dense in SNP markers (oral presentation of Canadian NRC and Dow works by S.M.H. Rizvi), and the desire to valorize the achievements. The Chinese (H. Wang, CAAS Wuhan), German (Rod Snowdon, University of Giessen) and Canadian (Isobel Perkin, Agriculture \& Agrifood Canada) public teams are very active in these approaches, as well as some private companies (Dow AgroScience, now Corteva for example).

Phenotyping was once again pointed out as a limiting factor in genome exploitation. Similar approaches have been developed in several countries: X. Pinochet presented a report on the French project PHENOME and its application for the research of rapeseed cultivars adapted to limited nitrogen availability (RAPSODYN Project), José Jimenez-Berni reported in Australia 2 sites under controlled conditions comparable to the French sites, and the development of a field phenotyping machine as in France. In Germany, the Jülich Institute has also equipped a site in controlled conditions and invested in automated pots. C. Bissuel also presented a method of rapeseed culture under controlled conditions to facilitate the evaluation of the nitrogen efficiency: this method usable for phenotyping greatly facilitates the characterization of the various organs of the plant, particularly the root system.

Nearly a dozen papers focused on obtaining hybrids, from the characterization of heterotic groups to optimize heterosis to results overviews for semi-dwarf hybrids, for example. Work on hybridization systems continued in China, with two new

\footnotetext{
${ }^{1}$ The following references [Chalhoub et al., 2014; J. Liu et al.; Rogiewicz et al.; Quinsac et al.; Kaushik et al.; Strelkov, Gossen et al.; G. Shi-xing et al.; Z. Huang et al.; Y. Liu et al.; Harker et al.; Génard et al.; Mikic et al.; Stahl et al.; Rudloff and Becker; Bouchereau et al.; Bouchet et al.; Niu et al.; Sorin et al.; Faralli et al.; Lemke et al.; Räbiger et al.; Dauguet et al.] correspond to communications made during the 2015 Rapeseed Congress and are available in the book of abstracts on www.gcirc.org.
}

cytoplasmic male sterility, one of which being temperaturesensitive, and even a communication about self-incompatibility.

Pod shattering also remains a highly worked subject, particularly in India and China, where the problem remains crucial on Brassica juncea particularly. Chinese teams (J. Liu et al., Chinese Academy of Agricultural Science, Wuhan) ${ }^{1}$ identified a new major QTL on A6 and confirm previous results on A9. Canadian researchers have also searched for QTLs on yellow seed material, featuring effects related to introgressions from B. rapa and B. carinata (S. Vail, AAFC). These QTLs are very environment-specific, do not seem to be related to introgressions, and are not located on the liaison groups identified by the Chinese teams.

A specific Workshop was dedicated to emerging technologies, highlighting the rapid ramp-up of CRISPR CAS9 genetic engineering technologies, discovered in 2012, and the abandonment of older targeted mutagenesis technologies such as TALEN or Zn Finger restriction enzymes.

The potentialities of this new technology will appear fully at the 2019 Congress and will certainly be worthy of a perspective for which many interventions of 2015 can provide elements. In fact, there were several trends that were contrary to the valorization of biotechnology applications.

P. Phillips (Univ. Saskatchewan) gave a very positive assessment of herbicide-resistant canola in Canada since the early innovations of the 1990s, which have increased yields but also led to profound changes in cropping systems (intensive systems without tillage). At the end of 2013, these varieties accounted for about $95 \%$ of canola in Canada, growing from 3.6 Mha in 2002 to more than 8 Mha in 2014. According to Phillips, producers who have adopted GM canola have indeed reaped a series of economic gains: no-till systems have increased from $11 \%$ of surface area in 1999 to $65 \%$ currently, resulting in a $72 \%$ reduction in tillage costs. Taking into account the gains on subsequent crops, the profits are estimated at Can $\$ 350$ 400 million per year. These elements were confirmed by Saskatchewan farmer Maurice Delage, who highlighted two breakthroughs in the performance of canola: herbicide tolerance, which has allowed him to practice simplified tillage in one pass for 20 years and the development of hybrids with very good potentials and improved stress tolerance. Phil Mc Donald of the Canadian Inspection Food Agency reported that 95\% of Canadian canolas are herbicide resistant, with Roundup Ready accounting for $65 \%$ of surfaces, Liberty Link $20 \%$ and Clearfield $18 \%$. Canada had also approved two new mutagenic herbicidetolerant varieties and several cisgenic variety applications were under review. These successes, however, present weaknesses: on weeds issue, if $95 \%$ of farmers believe that control has been improved, $76 \%$ report problems of resistance. Short rotations also contributed to the emergence of weed resistance to herbicides ( $N$. Harker, Keynote). Of the three weed control solutions used in Canada (Clearfield ${ }^{\circledR}$, Liberty Link ${ }^{\circledR}$ and Roundup Ready ${ }^{\circledR}$ ), only glufosinate (Liberty Link ${ }^{\circledR}$ ) was not yet concerned by resistant weed species. On the other hand, many species have resistance to imidazolinone (Clearfield ${ }^{\circledR}$ ) and some to glyphosate (Round-up ${ }^{B}$ ).

P. Phillips, however, considered that if in the past technology has generated value, in future the impacts of other contextual elements will be more important: developments in comparative advantages in business relationships, regulatory systems, evolutions in industrial systems generating doubts. 
For example, partial adoptions (25\% of countries accepting GMOs for food use, but $12 \%$ at the environmental level) hurt consumers and innovators, and regulatory complexities increase delays while marketing opportunities decrease.

These regulatory aspects persist today, with North American and European approaches based on different fundamentals. Phil Mc Donald of the Canadian Inspection Food Agency (Keynote) explained the Canadian regulatory framework for biotechnology introduced in 1993, based on the product. The first criterion taken into account is the "new" aspect of the product and the assessment is based on the concepts of familiarity and substantial equivalence, with reference to a "familiar witness". What is considered fundamental is the newness of the introduced traits and the possible generation of a risk, and not the fact that it is GMO or not (unlike Europe).

S. Yarrow and C. Moran of the trade association Crop Life Canada presented the practical implications of the biotech regulations: there were 28 countries using biotechnology in the field. Lack of authorization synchronization is causing problems for exporters as bulk handling systems have not been designed to separate varieties, but minimizing unpredictability is becoming a key to accessing the market. In the end, biotechnology developers are reluctant to certify "traits" in Canada (which is a major exporter, therefore a source of potential problems), which tends to dampen innovation. The industry therefore called for an international policy on lowlevel presence. The industrialists gathered in the Global Alliance for Agricultural Biotech Trade, and the exporting countries in the Global Low-Level Presence Initiative to officially recognize that the low presence is a question of compliance and not a health issue and redefine the "zero" in order to eliminate commercial refusals related to simple detection.

Other regulatory aspects can hinder the improvement of rapeseed at the other end of the value chain: that of genetic resources and varietal creation. Petra Jorash, from the German seed association, spoke about the issue of intellectual property policies, on the premise that IP is one of the 3 pillars of genetic innovation with technology and access to genetic diversity. European legislation allows the patenting of a trait or technique but not a variety, unlike US legislation. In fact, there is an optimum for the level of protection before and after which innovation is curbed. While the Plant Variety Protection (PVP) protects a unique combination, the patent protects the components of the combination: patents would restrict access to genetic diversity, in comparison with PVP.

The developments that had just taken place at the level of the European Patent Office showed inconsistencies. In a case law, cross-breeding and selection processes, which are biological in nature, were not patentable, unlike techniques of genetic transformation and mutagenesis. In a second case law, the plants were considered as the result of crosses and selection, and the "native traits", products resulting from these processes, considered as patentable... In $2015,30 \%$ of the patent applications included claims of "native traits", both in agriculture and horticulture. The proliferation of patents would restrict access to genetic resources: a balance needs to be struck between protection and access.

Petra Jorash also discussed the differences in genetic resource management in the CBD Nagoya (Convention on
Biological Diversity/Nagoya Protocol) and ITPGRGA (International Treaty on Plant Genetic Resources for Food and Agriculture) systems. In particular with regard to fields of application and exceptions for breeders. Nagoya refers to all plant resources, while the ITPGRGA only considers a number of species and crops for food and feed, Nagoya imposes much more precise descriptions. Here again, the stakes for access to genetic resources are significant.

In terms of perspectives, these elements concerning the field of genetics raise questions on several levels. First, the economic gains observed in Canada resulting from the introduction of herbicide-resistant GMOs question the competitiveness differentials at the level of production between geographic areas related to the adoption or not of the innovations as long as the market of consumption remains free and open, which has remained the dominant case so far for most traits of genetic transformation. Knowing that the free and open nature of the market remains linked to specific authorizations for each trait and creates commercial uncertainties in the event of accidental contamination.

In future, CRISPR Cas9 genetic engineering technologies promise a significant acceleration of genetic progress over a broad range of characteristics well beyond herbicide resistance. Work is in progress on the efficiency of nitrogen or water, nutritional criteria, etc... The evolution of regulations in Europe in particular will be decisive for the evolution of the relative economic competitiveness of rapeseed in different countries both at the level of production, as in recent decades, but also at the level of the market on qualitative criteria. However, the current trend under the pressure of opinion is to be more and more restrictive, as shown by the judgments of the European Court of Justice of July 2018 on mutagenic varieties, which raise the question of the obsolescence of Directive 2001-18 with regard to the advancement of scientific knowledge and technologies.

The massive use of broad-spectrum or total herbicides, with the adoption of no-till techniques, in North America with herbicide-resistant GMOs, but also in Europe where the same molecules are used in intercropping, have induced structural transformations of production systems. The weakening of these techniques, in the event of a rise in the population of resistant weeds, or their disappearance due to regulatory changes as it is emerging in Europe for glyphosate, question the agronomists about the technical sustainability of these systems and the support actions, alternatives and evolutions to consider. The world of rapeseed also has an increased need for systemic agronomy.

Finally, the elements relating to the access to genetic resources will be decisive for the dynamics of varietal creation, be it because of the evolution of the regulations and jurisprudence in the matter of plant variety protection, patentability of life and/or the agreements on international transfers. Here too, the subject goes beyond rapeseed.

\section{Tomorrow's outlets: Processes at the front-line}

At the other end of the value chain is the question of the future of rapeseed markets. F. Isermeyer (Keynote) presented an analysis of global trends and prospects for rapeseed, 
highlighting the impressive developments observed in recent years for palm oil and soybean production and the main characteristics of international trade: soybean and soybean products are much more developed than rapeseed, one of the main reasons being the attitude of Europe, strongly present in the position of importer of soya, but consuming internally most of its rapeseed, especially for biodiesel. Soy is much more fuelled by food use than canola. The FAO outlook forecasts strong demand for food and feed, while the recent development of rapeseed relied heavily on biodiesel, driven by public policies whose future is in question. F. Isermeyer noted that few economists have attempted to evaluate the correlation between "petroleum prices and rapeseed prices", but that as biofuels will always remain quantitatively very small vis-à-vis petroleum, high petroleum prices will lead to higher prices for biofuels. As the era of fossil fuels is likely to continue, including coal, public policies will probably come up again on the greenhouse gas aspects. He considers that in the long term, biofuels are unlikely to find a place in the energy mix, and that in the medium term, they depend on protective policies. If these measures are to disappear, Europe should become an exporter of rapeseed in highly competitive markets but it will be difficult to compete with the countries already exporting. Bioenergy should act as a stabilizing instrument for food market prices. F. Isermeyer summarizes the situation by the following elements:

- canola expansion is in line with soybean and palm;

- soybean and palm dominate trade;

- as far as uses are concerned, there has been a strong development of bioenergy;

- the perspectives are strong needs in food and animal feed;

- the development of the biofuels market is unlikely;

- in terms of yield increase, palm is superior to rapeseed which is higher than soybean;

- finally, the rapeseed meal remains low vis-à-vis the soybean meal. If soy is supported by proteins, it will put pressure on oil prices.

F. Isermeyer concluded that the rapeseed protein fraction deserves more attention and that the discussion should focus on market segmentation. This conclusion was similar to that of the prospective scenario of vegetable oils and proteins 2030 presented by E. Pilorgé (Pilorgé and Muel, 2016): in the long term, food remains the basis of competitiveness of rapeseed, and attention must be maintained on food oil and proteins for animal feed, even food. The oil fraction remains in question and some of the oil-side development is expected to go through oleochemistry (probably more value-adding than biofuels), due to the expected abundance of palm oil.

The contributions on the theme "Chemistry, processes and uses" showed an active research both for the improvement of the competitiveness on the traditional outlets and formore prospective ones, the evolutions of the context being quite taken into account, with a strong emphasis on the protein fraction, much more illustrated in this Congress than the oil fraction.

\subsection{On the protein side: Cakes in mass markets and new explorations}

The improvement of rapeseed meal remains the key to competitiveness in the mass market of animal feed and involves both genetics and the improvement of industrial processes.

An overview of the current and future value of Canola meal $(\mathrm{CM})$ in animal feed was done by D. Hickling. The largest market in North America is ruminants, particularly dairy cows in California. CM favors milk production more than soybean meal, and the reasons for this would be the higher level of ingestion, the high proportion of undegraded protein in rumen, and the stimulation of activity in the rumen. According to D. Hickling, the nutritional values of $\mathrm{CM}$ should be reassessed. A meta-analysis shows that in CM, the level of non-degraded protein in rumen is not related to the heat treatment of the cake (toasting).

On the same subject, various similar French works for the use of rapeseed meal on ruminants were presented: a reassessment of the nitrogen value and its prediction by $P$. Chapoutot (AgroParisTech, France), the measurement of the impact on the quality of milk and goat cheese (C. Hurtaud, INRA-Agrocampus, France) and the technical-economic comparison of rapeseed and soybean meal in 84 paired farms (C. Teinturier, France).

Aquaculture in Asia is the second outlet for Canadian CM according to D. Hickling. The herbivorous (carp) and omnivorous (tilapia, catfish) fish tolerate a fairly high level of antinutrients (AN) such as glucosinolates, phytates or fiber and their diet may contain 50\% CM. In contrast, CM does not enter feeds for carnivorous fish species that are more sensitive to $\mathrm{AN}$ and require higher protein concentration. The use of $\mathrm{CM}$ in pigs and poultry still causes formulation problems because the digestibility of amino acids (AA) can be reduced by the process and the AN. In fact, CM is not incorporated at more than $10 \%$ in growing chicken feed, but it can be incorporated for $15-20 \%$ in layer feed (Rogiewicz et al.) ${ }^{1}$.

According to D. Hickling, improving the nutritional value of $\mathrm{CM}$ requires decreasing $\mathrm{AN}$ and increasing the digestible protein content. Dehulling before deoiling or after (front- or end-tail dehulling) does not ultimately create enough surplus value to be economically viable. Genetic selection is an effective means and an example of improvement has been cited with the Dow AgroSciences canola that gives meals low in fiber and close to soybean meal without loss of agronomic yield in oil. Other alternatives are processes: temperature reduction during the process to avoid insolubilization of proteins, control of particle size to improve digestibility, extraction of proteins to obtain concentrates or isolates, use of enzymes.

The characterization of cakes and the study of their use in animal feed remains the subject of sustained works. Dietary fibers and their impact on the dietary value of the meal were synthesized in a Keynote by B. Slominski (University of Manitoba, Canada). The fiber content of rapeseed cake, which is naturally quite high, can be further increased during the process by the recycling of impurities and by the Maillard reaction which associates them with proteins. The fiber reduction can be achieved with yellow seeds or by dehulling. The comparison of yellow seeded varieties (Brassica napus and $B$. juncea) with a conventional black seeded (B. napus) variety was conducted by M. Radfar (Manitoba, Canada) on chickens. The protein contents of the prepared meals were $43.4,47.2$ and $41.1 \%$, respectively. $B$. juncea yellow seed cake had the best values of metabolizable energy, amino acid 
digestibility and zootechnical performance. B. napus yellow seed cake was intermediate and black seed cake was the worst.

The digestibility of proteins or amino acids, which represents a strong challenge, both economic and environmental, was the subject of work of several teams. S.K. Jensen (Univ. Aarhus, DK) showed on a pool of 30 varieties of winter rapeseed and 8 of spring rapeseed that the digestibility of rapeseed meal protein was positively related to the total protein content. This is explained by the very low digestibility of the proteins of hulls, whose presence in the seed is inversely proportional to the protein content. F. Schöne (TSIA, Jena, Germany) studied the effect of toasting during the desolventization at the Creol pilot (France). With pigs he found a correlation between the glucosinolate content and the ileal digestibility of the proteins: an optimum treatment degrading sufficiently the glucosinolates is worth considering with the help of the amino acid supplementation. D. Adewole (University of Manitoba) observed the same effect on pigs and chickens by comparing 11 conventional crushing plants with significantly different heat treatments. K. Kozlowski observed the adverse effect of heating on ileal digestibility of AA from deoiled cakes compared to unheated cakes. Houdjik (SRUC, Edinburgh, UK) confirmed this effect and extended the comparison to different varieties of rapeseed by showing that the process effect was by far superior to the variety effect. All these works show the difficulty of mastering the desolventization-toasting process to reduce the action of glucosinolates and to safeguard the digestibility of amino acids.

The digestibility of phosphorus remained a subject that was treated very little despite the issue of the level of releases in livestock effluents. The only communication (M. Vilarino, Arvalis, France) showed the additivity of the phosphorus digestibility of rapeseed meal and cereal grains in pig feed formulation.

In terms of anti-nutritional factors, genetic reduction of sinapine was considered by C. Jung (University of Kiel, Germany) from mutations: seeds with three times less sinapine could be produced in F3.

\subsection{Towards new markets through protein extraction}

The valorisation of rapeseed proteins beyond the traditional uses of oilseed cakes has been clearly posed as a challenge. The first findings are encouraging and show that the rapeseed proteins have a relatively well-balanced amino acid profile, that these proteins have interesting and unusual functional characteristics, that there is exploitable natural variability of the proteins in the Brassica genus and leeway in terms of breeding to improve rapeseed meal for protein extraction and bioavailability. The rapeseed fractionation methods studied by the PPM pilot (D-Magdeburg) were presented by F. Pudel. Conditions favourable to the preservation of proteins before their extraction were identified: yellow seeds with low fiber content, dehulling, $\mathrm{CO}_{2}$-assisted pressing, gentle desolventizing. Very pure napine and cruciferin fractions can thus be obtained and could be used in human nutrition or for technical applications. It should be noted that the Canadian company Burcon (M Schweitzer, Winnipeg) has been marketing for the last few years three products
(Supertein $^{(B)}$, Puratein ${ }^{\circledR}$ and Nutratein ${ }^{\circledR}$ ) containing napin, cruciferin and a mixture of the two, respectively. Napin is rich in sulfur and is a good foaming agent, the cruciferin a good emulsifier and the mixture, well balanced in amino acids can be used in human nutrition. The POS Bio Sciences (pilot plant of Saskatoon) is also working on the fractionation of rapeseed proteins and works on isolation and on the study of napin properties (including flocculation) were presented by J.P.D. Wanasundara (see Wanasundara et al., 2016). Considering the high cost of water removal in extraction processes, dry fractioning or concentrated solution was studied by K. Rommi (VTT, Finland). In addition to the presentations in sessions, a specific workshop has been held on the subject, reported by L. Campbell et al. (2016) in the journal Plants. Despite the nutritional and functional interest of these concentrates and isolates, and the investments of the process research teams of two major producing countries (Canada and Germany), the market for these products did not seem mature in 2015 to have a production at an industrial scale. The first challenges are the analysis of the potential market and a better understanding of the competitive advantages of rapeseed proteins. It is noted, however, that the desolventized cake presently produced by industry is an inefficient material for protein extraction under economic conditions, again raising the issue of oil extraction processes. Finally, in the context of the evolutionary landscape of protein-rich products, rapeseed proteins should be considered for their own characteristics and not only in a rapidly limiting approach to replacing protein ingredients of animal origin. However, it should be noted that the "GMO fracture" between regions of the world is likely to be expressed more strongly on products intended for human consumption than on cakes intended for animal feed or on oils.

In terms of the outlook for the protein fraction, ruminants remain the most accessible market for oilseed cakes. The prospects for growth in aquaculture - linked especially to the depletion of marine resources and the increase in consumption - are particularly interesting for the oilseed cakes market, but in a different way in different parts of the world: the aquaculture of herbivorous or omnivorous species is first and foremost the fact of Asia and Africa.

The continued improvement of oilseed cake remains a challenge of competitiveness both for environmental reasons (limitation of nitrogen and phosphorus emissions from farms, by improving digestibility) and technical and economic reasons: the increase in the content of biologically available proteins, through genetics and/or processes, is at the same time a challenge of competitiveness on the oilseed cakes market and an economic obstacle in the perspective of developing the proteins' extraction.

\subsection{Regarding the oil fraction}

A Keynote by W. Loh and L. Debonte (Cargill USA) reviewed the development of high oleic varieties beginning in 1993, which accounted for $15 \%$ of Canadian canola acreage between 2010 and 2015, mostly developed under contract and not competing the conventional canola acreage. Due to the reformulations of the agri-food industries and catering companies, this development seems to have made it possible to substitute annually for 135000 tons of trans fat and 
126000 tons of saturated, inducing significant health benefits. However, this outlet is competing with oleic soybean oils. Loh concluded on the interest of new types of oils in future to create value by meeting the consumers' needs and regulatory changes.

The minor compounds of the oil are also the object of attention in order to preserve them during the process and to develop them: a method of detection of the minor compounds of interest in the oil (sterols, tocopherols, carotenoids) by HPLC-MSMS was developed by C.L. Flakelar (Wagga Wagga Univ., Australia) for genetic screening. A NIRS calibration should become available and facilitate the evaluation of process and storage effects. The phenolic compounds (gallic acid, caffeic, sinapic, ferrulic, etc.) interesting from a health point of view for their anti-oxidant effects, have been analyzed by F. Ma (OCRI, Wuhan, China) by solid phase extraction with magnetic adsorbents and by HPLC-MS/MS. This simple and fast method allows to measure these compounds during the oils refining and thus to limit their degradation.

On the sensory quality side, a contribution to the sensory analysis of virgin cold pressed oils is provided by B. Matthäus (Max Rubner Institute Detmold, Germany) by analysis and identification by Dynamic Headspace and GC-MS of 41 volatile compounds of which 23 are related to the sensory quality of the oil. The analysis of the volatile in rapeseed oil by C. Liu (OCRI, Wuhan, China) shows that a majority comes from the degradation of glucosinolates and that the process of obtaining the oil has a great influence on their composition.

In terms of technological quality, Matthäus also plans to improve the frying performance of oils by using the antioxidant effects of canolol extracted from the cake in which it was formed during thermal treatments of the crushing.

For sanitary quality, the contamination of oilseed rape seeds by cadmium and its migration was monitored by X. Ding (Oil Crop Research Institute, Wuhan, China) with nearly 600 samples collected in 11 at-risk regions. The levels in the seeds are less than $0.2 \mathrm{ppm}$ in $99 \%$ of cases (Chinese standard at $0.5 \mathrm{ppm}$ ) and the proportion transmitted to the oil varies from 2 to $10 \%$. The authors conclude that there is no risk even in case of soil contamination. A rapid and sensitive immunochemical test $(0.1 \mathrm{ng} / \mathrm{ml})$ on a strip to detect Aflatoxins B1 is also described by Z. Zhang (OCRI, Wuhan, China). Finally, a chemometric method based on the analysis of 28 fatty acids makes it possible to detect the adulteration of rapeseed oils from a level of $12 \%$ (L. Zhang, OCRI). A more sensitive method (threshold 10\%) is used by B. Xu (OCRI, Wuhan China) by analyzing phytosterols by multidimensional GC and time-of-flight mass spectrometry (GC-GC-TOF/MS).

In the extraction processes, alternative solvents (ethanol, isopropanol) were compared with hexane for extraction of the oil in a semi-continuous process by Quinsac et al. ${ }^{1}$ (Terres Inovia, France). The oil is extracted with a good yield and the cake produced is enriched in proteins by about 4 points, but the recycling of the solvent is made difficult by its hygroscopy and the accumulation of the water extracted from the treated material. The behaviour of rapeseed during static pressing was studied by L. Bogaert (UTC, France) in order to model this operation and to define the optimal conditions for the pretreatment of the seeds. The results make it possible to envisage research on dynamic pressing to improve the performance of current screw presses operating in continuous mode.

\subsection{Towards biorefining approaches for rapeseed?}

Most presentations were guided by an oil or protein concern. Some are distinguished by exploring the valorisation of other elements contained in rapeseed. Screening for the presence of bioactive compounds in Canola meal (protease inhibitors, anti-oxidant, anti-cancer, anti-obesity, anti-diabetic, anti-hypertension activities) was carried out by S. Hussain (Charles Sturt Univ., Wagga Wagga, Australia). The Glucosinolates (GSL) extracted from mustard was tested by Kaushik et al. ${ }^{1}$ (TERI, New Delhi, India) for the control of moth in the framework of the APROPOS project (FP7/289170) whose objective is the valorisation of the co-products of the rapeseed and fish industries (http://www.euapropos.eu/). The biofumigation effect of glucosinolates was tested by Y.S. Jang (Bioenergy Crop Research Institute, Muan, Rep. Korea) on nematodes using oily meal.

The production of polyhydroxybutyrate (PHB) biodegradable polymers from camelina seeds was presented by $\mathrm{M}$. Malik (Metabolix Oilseeds Inc., Saskatoon). A yield of $15 \%$ of the seed weight was obtained.

It should be noted that the uses of oils in biofuels have not been the subject of developments at the Congress, apart from the evaluation of their energy and greenhouse gas balances.

\section{Sustainability of production: Worrying developments in crop protection}

For the needs of agricultural practice, the production of knowledge on the biology of different pests is a necessary step for both the development of genetic resistance and agronomic solutions.

In terms of diseases, the two stars of the Congress were the Leptosphaeria, which is still undergoing sustained work, and the clubroot, for which there is a rise in importance.

Leptosphaeria has been the subject of 40 communications, and has expanded in China, which was not affected until recently. The research is oriented on the one hand towards the effectors from RNA sequencing, and on the inventory of populations characterized by their virulence profiles. This type of study conducted in France in the 2000s has multiplied in Europe as well as in Canada. In particular, the overcoming of $\mathrm{R} \operatorname{lm} 3$ resistance in Canada was noted. China is also undertaking work on this topic.

The clubroot Plasmodiophora brassicae was undoubtedly one of the major points of this Congress with 35 communications. The first 3 canola producing states in Canada are facing very serious problems, and the pathogen is also growing in Europe (Germany, Poland, Sweden and the Czech Republic) and in China (Sichuan). Canadian work has confirmed aspects already known in Europe about the effects of liming, rotation, and transmission. Inventories of pathotypes present or dominant in certain regions have been made (Canada, Germany, France). Among the most original points are the possible contaminations, although in minority, by the dust clouds of the Great Plains (Strelkov, Gossen et al.) ${ }^{1}$. Work has also been done on the development of qPCR methods for quantifications, with studies of spore number variation depending on the crops in the rotation, including a Swedish paper containing counts of soil samples that have been 
conserved for 40 years, showing the explosion of the number of spores linked to the rapeseed crop, and then the decrease in the context of a lengthening of the rotation. Public and private research (Pioneer, Syngenta, Monsanto, NPZ) allocated great efforts to find and introduce new resistances. New sources of resistance have been announced, with pyramiding of 3 different genes. A Chinese team (G. Shi-xing et al. $)^{1}$ expressed dismay at finding only 2 potential sources of resistance in a screening of 279 genotypes. A Canadian team developed markers for the introgression of 7 major resistance genes from B. rapa or B. nigra located on Liaison Groups A3, A8, B3 and $\mathrm{C} 7$ to address the urgency of finding genetic solutions. A team from Edmonton, Alberta, exploited crosses with rutabaga, which provides sources of resistance against all pathotypes in western Canada. Synthetic amphidiploid strategies were developed in Saskatoon using sources identified in B. rapa, $B$. nigra and $B$. oleracea (Z. Huang et al. $)^{1}$. These sources would confer resistance to many pathotypes. A QTL approach is presented by a China-Canada-Pioneer consortium with the location map of both major genes and QTL (H. Zhang et al. $)^{1}$. For the short term introgressions of $\operatorname{Rcrl}$ (B.rapa) were described with tracking by markers. In another study Rcr4 would control the 5 main Canadian pathotypes. Another communication from the Saskatoon teams identified Rcr6 and Rcr8 in B.nigra with associated SNPs. On the pathogen side, with sequencing, a Canado-Anglo-Iranian study looked for effectors and hypothesized to have avirulence candidate genes. In Poland M. Jedryczka's group presented a picture of the situation and perspectives of diagnosis with q PCR and LAMP from the soil. A. Laperche (France) presented results showing modulations of QTL effect as a function of $N$ stress and pathotype. A Chinese team (Y. Liu et al. $)^{1}$ tested an efficient, but undescribed, seed coating.

Clubroot is a growing topic and has been the subject of several dedicated workshops in Canada and Germany since the 2015 conference.

Although not having the importance expected in this Congress, Sclerotinia was rather present especially with 2 summary presentations by M. Barbetti and I. Falack. The main advances are in the identification of pathotypes with the definition of a set of differential hosts, in the application of association genetics for the identification and selection of resistance factors, and in the description of a new GMO strategy by a Chinese team (Wuhan) on a subject already rich in strategies of this type.

Most of the work presented has been focused on diseases considered as major: apart from works on phoma, clubroot and sclerotinia, there was only one poster on Verticillium presented by C. Obermeier (Univ. of Giessen, Germany) on research for QTL resistance and production of markers transfered to German seed companies, and a poster on albugo by an IndoCanadian team (characterization of the genetic diversity of Albugo candida isolates).

The chemical control of diseases was not much present, with only 3 posters on the assessment of the sensitivity of phoma to azoxistrobin (University of North Dakota) for fear of resistance, on the characterization of sclerotinia isolates for approving fungicides in Australia, on an unspecified seed treatment to control clubroot (China).

Finally, quite a bit new, some works on rapeseed biocontrol solutions were presented: work on the use of mycovirus against sclerotinia (University of Wuhan, China), use of Trichoderma in laboratory tests on rape seeds... (Serbia) and Pseudomonas chlororaphis against sclerotinia in greenhouse tests on petals, (University of Manitoba, Canada).

Insect control is crucial for rapeseed production and gets back a new importance as traditional insecticide solutions wear through the emergence of resistant populations, and because of regulatory restrictions or prohibitions on several families of molecules, the latest on neonicotinoids: following a moratorium in 2013, thiametoxam, clothianidin and imidacloprid are now banned in Europe for field use on all crops, and Canada plans to eliminate them by 2023 .

The case of controversial neonicotinoids was widely discussed at the 2015 Congress: Heimbach presented studies conducted in Germany on the effect of neonicotinoids on pollinators (Keynote) pointing out that the ban on their use in seed treatment had led to a $500 \%$ increase in the use of pyrethroids, an increased risk of resistance of the stem flea beetle and a reduced rapeseed acreage. However, according to the presented results, there was no increase in the mortality of bees living near rapeseed plots whose seeds were treated with neonicotinoids. The concentrations found in pollen and rapeseed nectar were indeed low $(<1 \mathrm{ppb})$. Higher concentrations have been found in droplets from the guttation of plants, but bees have other sources of water supply. According to the German studies, the main risk came from neonicotinoid dust contamination during sowing, which can be controlled by a quality coating, more than from the recovery of active ingredients in the nectars and pollen of cultivated plants. In the United Kingdom, the ban on seed treatment with neonicotinoids had also contributed to reduce rapeseed surfaces (Nicholls, workshop). In addition, 3\% of the surfaces were ploughed due to flea beetle damage and the resistance of these insects to pyrethroids is progressing.

In Canada, Sekulic (Workshop) also found pollen concentrations $<1 \mathrm{ppb}$ and in $68 \%$ of cases no residues at all. In France, field studies (Cerrutti, workshop) showed that thiamethoxam insecticide reduced the longevity of honeybees, but these disturbances at the individual level did not have visible repercussions on the performance of colonies. Honey production, population levels and the health status of the colonies were not affected. In this sense, the presented results are not contradictory.

The 2015 workshop therefore focused on the negative consequences in terms of the management of rapeseed pests related to the withdrawal of neonicotinoids and expressed strong concerns for the future of rapeseed. Disturbing observations and meta-analyses on the decline of insect populations in Europe and public opinion pressure have since won political decisions. Insect control should therefore be at the forefront of the 2019 Congress. Unfortunately, the development of alternative solutions to insecticide with comparable efficacy is complex.

At the 2015 Congress, the introductory presentation by Samantha Cook (University of Rothamsted, UK) called for the basics of integrated protection and mentioned a set of trails:

- the development of attractive traps, studied for pollen beetles, showed a good correlation between catches and plant infestations, to facilitate farmers' interventions;

- the development of resistant cultivars, probably the way for the future despite the difficulties encountered by breeders. 
In particular, the work of the INRA IGEPP (Rennes, France) on pollen beetles, the development of a Limagrain variety resistant to TuYV virus, the test of rapeseed plants with flowers of different colours were mentioned;

- push and Pull strategies (trap cropping);

- landscape management.

The pests studied in Canada are little or not present in Europe on rapeseed. A new pest, the swede midge (Contarinia nasturtii), posed many problems in Canada with attacks severe enough to recommend avoiding growing rapeseed for at least 3 years in affected areas. Initial work aimed at describing the area of distribution of the insect and natural enemies that could reduce population levels.

The number of papers on insect control has finally been quite limited, reflecting in principle a lack of R\&D investment, at least relative, and/or the difficulty of completing research. Although the pests are sometimes different, the approaches and levels of progress are broadly the same. The search for alternative strategies is laborious and has efficiency levels often insufficient to completely farm without the chemical. No major advances were presented. Expectations are particularly high on the development of resistant varieties.

\section{Sustainability of production: What roles for agronomy facing a greater need for the integration of knowledge and techniques?}

In Canada, canola is distinguished by its prominent place in rotations and the almost systematic use of herbicide resistant varieties. The most common rotation is rapeseed-wheat, followed by rapeseed-wheat-wheat or barley or peasrapeseed, and rapeseed monoculture (Harker, Keynote). Harker et al. ${ }^{1}$ conducted works to evaluate the effect of crops and rapeseed cultivars diversification on pests and rapeseed yield. The observed yields are linearly correlated with the number of years between two rapeseed crops $(0,1$ or 2 years), with a slope of 0.2 to $0.36 \mathrm{t}$-/ha/year. The study also shows a decrease in the presence of cabbage maggot flies and phoma symptoms with longer rotation. On the other hand, no effect on weed density was observed. Then in rapeseed monoculture alternating varieties in the rotation or mixing varieties had no effect. O'Donovan (Canada) also showed the positive effect on rapeseed of the introduction of legumes (protein peas, lentils, fababeans or fababeans fully used as green manure) in the rotation. For example, with a preceding pea or lentil, compared to a preceding wheat, the amount of $N$ fertilizer to reach a given yield level is reduced by $25 \%$. An effect on yield potential was also observed after pea and lentil compared to a preceding wheat. No interaction is found with the nitrogen dose suggesting that the legumes' previous effect is not related to direct nitrogen supplies. Short rotations also contribute to the emergence of weed resistance to herbicides: Harker advocates for more integrated weeding: direct seeding to limit weed emergence, band fertilization, increased seeding density of rapeseed, alternative control (harvest of small straws to eliminate weed seeds...) and diversification of rotations.

Results on rapeseed with companion legumes were presented by three teams. In France, rapeseed with a companion cover of legumes showed a reduction in weed cover and fall in insect damage, and an increase in the efficiency of nitrogen use (Cadoux et al., 2015). A team from the University of Caen showed under controlled conditions (Génard et al. $)^{1}$ that the amount of nitrogen in the soil increases with legumes, especially with lupine, to a lesser extent with clover and little or not with vetch. The share of legume nitrogen from fixation increases when legumes are combined with rapeseed, confirming the synergistic effect, but remains low for clover $(<50 \%)$. The association with clover increases the chlorophyll content of rapeseed leaves. Finally, rapeseed is competitive with legumes (biomass reduction) which could be explained by a decrease in availability of sulfur (the sulfur concentration is lower when legumes are associated). The third study (Mikic et al. $)^{1}$ focused on the interest of associating peas or vetch with rapeseed harvested as fodder. The combination makes it possible to increase the biomass and the quantity of protein harvested and thus has a development potential for this use.

Half a dozen presentations focused on improving the efficiency of nitrogen, which remains a major concern. The presented results confirmed a significant variability between rapeseed genotypes (Bouchereau et al.; Keynote, Stahl et al.; Rudloff and Becker) ${ }^{1}$. Stahl pointed out that the variability concerns both the efficiency of nitrogen uptake and the efficiency of use, and that they are independent: no genotype in their study showed both a good efficiency for the absorption and for use. The authors conclude that there is significant potential for improving nitrogen efficiency in rapeseed. The studies aim at identifying the processes involved in the efficiency of nitrogen (Bouchereau et al.) ${ }^{1}$ and at finding QTLs (Bouchet et al. $)^{1}$. In addition, a paper focused on the effect of climatic conditions and cultural practices on the nitrogen efficiency of rapeseed and mustard (Niu et al. $)^{1}$ with the aim of reducing $\mathrm{GHG}$ emissions.

A communication on the sulfur nutrition of rapeseed has also been presented (Sorin et al. $)^{1}$. The first response to a deficiency in this element is the decrease in concentration in the vacuoles which is compensated by an increase in nitrate, chlorine and phosphate ions, which allows to maintain the osmotic pressure, the growth, the absorption of nitrate and nitrate reductase activity. It is only in a second time, after ten days, that there is a reduction of osmotic pressure and associated processes. As a result, the authors proposed the development of an early indicator of sulfate deficiency based on the ratio of sulfate concentration to the sum of chlorine, nitrate and phosphate concentrations. On this theme, Sophie Brunel Muguet (University of Caen, France) has established a critical dilution curve of sulfur in rapeseed and developed a simulation model of the growth and sulfur content of rapeseed.

Mc Kay (Keynote) presented results regarding water efficiency. Variability was observed between rapeseed genotypes and a major QTL was identified. The author indicates that the observed differences are associated with variations in the sensitivity of the stomata opening to ABA. Promising results in improving water efficiency through the application of antiperspirants have also been presented (Faralli et $a l.)^{1}$. The authors point out that the first tests of antiperspirant application date back 50 years, but that the works were abandoned because of the depressive effect of these compounds on photosynthesis. Recent works on wheat, 
however, has shown that if antiperspirants were applied during the development period of the most drought-tolerant plant, they could increase yield. In rapeseed, Faralli et al. ${ }^{1}$ observed that the application of pinolene-based compounds increased photosynthesis, water efficiency and yield in water-deficient conditions, while decreasing photosynthesis of well water-fed control plants without reducing seed yield.

The issue of greenhouse gases (GHGs) has been the subject of several presentations, particularly because of the use of rapeseed oil to produce biofuels. This concern concerns the Canadian industry with a view to exporting production to European biodiesel manufacturers. For this reason, GHG emissions for different regions of Canada have been calculated (Rempel). The regions have more or less significant GHG values, but still lower than the default value published in the European Directive $\left(29 \mathrm{~g} \mathrm{CO}_{2} / \mathrm{MJ}\right)$. This variability results from differences in cropping practices and in the level of precipitation, as the method used in Canada to calculate $\mathrm{N}_{2} \mathrm{O}$ emissions takes this factor into account. Canada is one of the only countries to have developed a national method for estimating $\mathrm{N}_{2} \mathrm{O}$ emissions (IPCC Tier 2 method). The data used to develop this method were acquired on rotations dominated by wheat cultivation. The increase in rapeseed acreage in Canada justifies the question of the effect of the crop on emissions. Lemke et al. ${ }^{1}$ studied the effect of the crop and of the preceding crop. Their conclusions agree with the results obtained in France: protein pea emissions are at the same level as those of wheat not receiving $N$ fertilizer and lower than nitrogen-fertilized crops, with no difference between wheat and rapeseed receiving the same amount of $N$ fertilizer, and higher emissions after the rapeseed crop without possibility to attribute this difference to the soil nitrate content or the amount of nitrogen in the residues or the amount of fertilizer added to the following crop. Räbiger et al. ${ }^{1}$ focused on indirect emissions of $\mathrm{N}_{2} \mathrm{O}$ in Germany (emissions caused by nitrogen enrichment of natural environment due to losses from cultivated plots). Their work is based on the use of models to estimate nitrate leaching and $\mathrm{NH}_{3}$ volatilization. The calculated emissions are lower than those obtained with the IPCC Tier 1 method based on emission factors.

More global assessments than the contribution to global warming were also presented. In France, a public database has been designed to allow life cycle analyzes (Dauguet et al. $)^{1}$, as part of the AgriBalyse project. The presentation focused on the data sources and on the use of the database to calculate 4 environmental indicators of French rapeseed production: GHG emissions, fossil energy consumption, eutrophication and acidification. BASF (Weston) has also presented its AgBalanceTM tool which offers an assessment of the three pillars of sustainability (economic, environmental and social), as well as two examples of application of this method.

In terms of perspectives, managing the biofuel assessments and the impact of the crop itself on the environment in the context of climate change make works on the efficiency of the plant and crop in relation to resources (in particular nitrogen, sulfur, water) a prerequisite for the future. From this point of view, the use of phosphorus could be more strongly invoked in these concerns for the future. Moreover, the issues on the balance of cropping systems, particularly in terms of diversification and longer rotations, will be all the more crucial as the possibilities of artificialisation of the environment by inputs will be limited, on the one hand for the pests control with plant protection products, for both regulatory reasons and innovation dynamics, and on the other hand for plant nutrition with fertilizers for reasons of resource savings. It is therefore to be hoped that the works of agronomists for rapeseed will complement each other on the different scales of work from the plant to the cropping system, and even to the production regions.

\section{Production is in the field: Developments of decision tools and advice services?}

Models are often the basis of decision and advice tools. Very few presentations have been devoted to epidemiological models for both diseases and insects. In the field of crop models, a poster by W. Wenmann (University of Kiel, Germany) shows a particularly detailed phenological module (calculation of BBCH stages) based on Karla Muller's thesis (2008), with a description of the very complete ecophysiological processes that reminds of the French CERES-EGC model. We can notice a very good relation between the model simulation and observations. The model was not yet published. It was also used in T. Robiguer's oral presentation on $\mathrm{N}_{2} \mathrm{O}$ emissions.

Amélie Mathieu (UMR ECOSYS, France) presented in a poster a 3D architecture model at the stand scale. The stumbling block at that time was the lack of measurements to better understand the establishment of heterogeneities within a rapeseed stand.

S. Brunel-Muguet (University of Caen, France) developed the SuMoToRI model to predict the effect of sulfur deficiency on the growth of winter rape.

In the area of crop management tools, Pradip Das, of “Climate Corporation", a subsidiary of Monsanto's presented embedded tools for precision farming. The most innovative point consisted of dynamic model outputs (particularly the positioning of nitrogen fertilization) directly integrated into embedded tools and smartphone applications, which are expected to achieve strong development.

\section{Conclusions}

The 2015 Rapeseed Congress was strongly inspired by the two major themes rich in technological and scientific investments that are plant breeding and process industries.

In terms of genetics, the 2015 Congress saw the first applications of the new molecular techniques: 2019 should see a series of advances related to these techniques.

The increase in the biodiesel outlet and its relative fragility have highlighted the interest of enhancing the value of the meal co-product in order to guarantee the long-term competitiveness of the crop in the global context. Work on the protein fraction has therefore been strongly illustrated. Aquaculture, promising a bright future, reinforces the traditional uses of rapeseed meal, and other applications are emerging with the extraction of proteins: will the 2019 Congress see developments and a maturation of this market? With which segmentations? Whatever the type of use envisaged outside of animal feed for ruminants, the question of the evolution of oil extraction industrial processes remains essential for the development of coherent economic value chains valorizing the proteins. More 
broadly, is the promotion of rapeseed more oriented towards a biorefining type of integration? The Keynotes relating to the theme of production/agronomy were themselves largely based on the technological dimension: phenotyping and link with the expression of the genetics, precision farming and big data, innovations from biotechnology. Beyond the technologies, the mobilization of the agronomists is more than ever necessary for their assembly and the development of productive, efficient and low-impact rapeseed farming systems, a question that was relatively little discussed during the Congress. In crop protection, clubroot has come to the fore, and integrated insect control is a vital challenge for the crop. Rapeseed is grown in cereal cropping systems that are often not sufficiently diversified over time (crop rotation) and in space (crop distribution), with the risk of causing high parasite pressures. The often-rapid erosion of simple solutions, whether chemical or genetic, shows the urgency of working on more integrated paths associating the redefinition of cropping and production systems with the aim of reducing parasite pressures to levels manageable by solutions with generally partial effects, such as biocontrol.

\section{Acronyms}

$\begin{array}{ll}\text { AAFC } & \begin{array}{l}\text { Agriculture and Agri-Food Canada } \\ \text { CAAS/OCRI }\end{array} \\ & \begin{array}{l}\text { Chinese Academy of Agricultural Science/Oil } \\ \text { Crops Research Institute } \\ \text { Convention on Biological Diversity }\end{array} \\ \text { FBD } & \text { Food and Agriculture Organization } \\ \text { GCIRC } & \begin{array}{l}\text { International Consultative Group for Research } \\ \text { on Rapeseed }\end{array} \\ \text { IGEPP } & \text { Environment and Plant Protection (Inra, France) } \\ \text { IPCC } & \text { Intergovernmental Panel on Climate Change } \\ \text { NRC } & \text { National Research Council Canada }\end{array}$

$\begin{array}{ll}\text { PVP } & \text { Plant Varieties Protection } \\ \text { SRUC } & \text { Scotland's Rural College (UK) } \\ \text { TERI } & \text { The Energy and Resources Institute (India) } \\ \text { TSIA } & \begin{array}{l}\text { Thuringian State Institute of Agriculture } \\ \text { (Germany) }\end{array} \\ \text { UTC } & \begin{array}{l}\text { Université Technologique de Compiègne } \\ \text { (France) }\end{array} \\ \text { VTT } & \text { Technical Research Centre of Finland }\end{array}$

\section{Supplementary Material}

French version.

The Supplementary Material is available at https://www.ocljournal.org/10.1051/ocl/2019026/olm.

\section{References}

The contents of the Protein Workshop were published by the organizers: Campbell L, Rempel CB, Wanasundara JP. 2016. Canola/rapeseed protein: Future opportunities and directionsWorkshop Proceedings of IRC 2015. Plants 5: 17. Available from https://www.mdpi.com/2223-7747/5/2/17.

Several papers reported at the Congress were subsequently published in OCL Journal: Cadoux S, Sauzet G, Valantin-Morison $\mathrm{M}$, et al. 2015. Intercropping frost-sensitive legume crops with winter oilseed rape reduces weed competition, insect damage, and improves nitrogen use efficiency. $O C L$ 22(3): D302. DOI: $10.1051 / \mathrm{ocl} / 2015014$.

Pilorgé E, Muel F. 2016. What vegetable oils and proteins for 2030? Would the protein fraction be the future of oil and protein crops? OCL 23(4): D402. DOI: 10.1051/ocl/2016030.

Wanasundara JPD, McIntosh TC, Perera SP, Withana-Gamage TS, Mitra P. 2016. Canola/rapeseed protein-functionality and nutrition. OCL. DOI: $10.1051 / \mathrm{ocl} / 2016028$.

Cite this article as: Pilorgé E, Flénet F, Quinsac A, Pinochet X. 2019. From one rapeseed congress to another: what research for which issues, A review of the Saskatoon 2015 conference in the perspective of Berlin 2019. OCL, 26: 30. 